\title{
Hemorragia pulmonar y síndrome antifosfolípido primario: aportación de un caso y revisión de la literatura
}

\author{
P. J. MARCOS RODRÍGUEZ, C. MONTERO MARTÍNEZ, H. VEREA HERNANDO \\ Servicio de Neumología. Complejo Hospitalario Universitario Juan Canalejo. A Coruña
}

\begin{abstract}
RESUMEN
El síndrome antifosfolípido se caracteriza por la asociación de fenómenos trombóticos venosos y/o arteriales y un título elevado de anticuerpos antifosfolipídicos. Sus manifestaciones pulmonares más frecuentes son el tromboembolismo y la hipertensión pulmonar, pero recientemente también se han descrito algunos casos de hemorragia alveolar.

Aportamos un caso de hemorragia alveolar en el seno de un síndrome antifosfolípido primario. La primera manifestación en este paciente fue una trombosis venosa profunda del miembro inferior derecho. Posteriormente presentó esputos hemoptoicos de forma persistente y la radiografía mostró infiltrados alveolares. La broncoscopia descartó otras causas de hemoptisis y el lavado broncoalveolar confirmó que se trataba de una hemorragia alveolar ( $80 \%$ de hemosiderófagos). Se discute el caso y realizamos una revisión de la literatura.
\end{abstract}

PALABRAS CLAVE: Síndrome antifosfolípido. Hemorragia alveolar.
PULMONARY HAEMORRHAGE AND PRIMARY ANTIPHOSPHOLIPID SYNDROME: CASE REPORT AND REVIEW

\section{ABSTRACT}

The antiphospholipid syndrome is defined by the association of vein and/or arterial thrombotic events and a high level of antiphospholipid antibodies. Pulmonary embolism and pulmonary hypertension are the most usual complications and recently some new cases of alveolar haemorrhage have been described.

We present the case of an alveolar haemorrhage in a patient with a primary antiphospholipid syndrome. The first manifestation of this patient was a deep vein thrombosis on his left lower leg. After that he had persistent hemoptoic sputum and his chest $x$-ray showed alveolar infiltrates. The bronchoscopy ruled out another causes of haemoptysis and the bronchoalveolar lavage confirmed that it was an alveolar haemorrhage (80\% of hemosiderophages ). The case is discussed and we do a literature review.

KEY WORD: Antiphospholipid syndrome. Alveolar haemorrhage.

Marcos Rodríguez PJ, Montero Martínez C, Verea Hernando H. Hemorragia pulmonar y síndrome antifosfolípido primario: aportación de un caso y revisión de la literatura. An Med Interna (Madrid) 2007; 24: 125-128.

\section{INTRODUCCIÓN}

El síndrome antifosfolípido es una entidad caracterizada por la asociación de fenómenos trombóticos (arteriales y/o venosos), abortos o pérdidas fetales de repetición y elevación sérica persistente de anticuerpos antifosfolipídicos (anticoagulante lúpico y anticuerpos anticardiolipina) (1). Este proceso puede observarse en el contexto de algunas enfermedades autoinmunes, como el lupus eritematoso sistémico, el síndrome de Sjögren y la esclerosis sistémica (2), o asociado a neoplasias, infecciones o como reacción a algunos fármacos. Cuando no aparece relacionado con las entidades reseñadas lo clasificamos como síndrome antifosfolípido (SAF) primario o idiopático (3).

Las complicaciones pulmonares más frecuentes son el tromboembolismo pulmonar y la hipertensión pulmonar tromboembólica (3), seguidas de manifestaciones no trombóticas como hipertensión pulmonar no tromboembólica, síndrome de distrés respiratorio y hemorragia alveolar (4-8).

La hemorragia alveolar es excepcional. En una búsqueda bibliográfica en la base de datos Medline a través de Pubmed (1966-marzo 2006) usando las palabras "alveolar haemorrhage”, "pulmonary capillariris” y "antiphospholipid syndro$m e$ ” encontramos 20 casos. Es posible que por lo abigarrado 
de las manifestaciones clínicas, en muchas ocasiones este síndrome pueda pasar inadvertido y que sus síntomas se atribuyan erróneamente a otros procesos.

Aportamos un nuevo caso de hemorragia pulmonar en un paciente con el SAF primario y realizamos una revisión de la bibliografía.

\section{CASO APORTADO}

Varón de 52 años que como antecedentes personales destacaba que era un exfumador de 10 cigarrillos/día y había sido diagnosticado de válvula aórtica bicúspide con función sistólica normal. Un año antes fue intervenido de diverticulitis de sigma aguda con perforación y peritonitis y a los 4 meses de la intervención presentó una trombosis venosa profunda (TVP) fémoro-poplítea derecha, recibiendo desde entonces tratamiento con acenocumarol. El estudio realizado a los 3 meses del episodio para descartar un síndrome de hipercoagulabilidad mostraba un tiempo de protrombina (TP) de $12,67 \mathrm{seg}$ (VN 9-12 seg) un tiempo de tromboplastina parcial activada (TPTA) de 66,23 seg (VN 26-39 seg), las plaquetas $140.000 / \mathrm{dL}$, anticuerpos anticardiolipina de tipo Ig G 127 GPL/mL (VN 3,2-16,5) y anticuerpos anticardiolipinas de tipo IgM de 9,2 GPL/mL(VN 3,941). Los niveles séricos de antitrombina III, proteína $S$ y proteína $C$ fueron normales.

Consulta por un cuadro de astenia y fiebre intermitente de $38^{\circ} \mathrm{C}$ desde un mes antes y que en los 4 días previos al ingreso había comenzado con expectoración hemoptoica, disnea de moderados esfuerzos y la fiebre se había echo persistente. En la exploración física presentaba un buen estado general, destacando únicamente una temperatura de $38^{\mathrm{a}} \mathrm{C}$ y $\sin$ otras alteraciones relevantes salvo la colostomía.

La analítica mostraba una hemoglobina de $14,5 \mathrm{~g} / \mathrm{dL}$, hematíes $4.650 .000 / \mathrm{mm}^{3}$, volumen corpuscular medio $89,7 \mu \mathrm{mc}$, el número de leucocitos 8170 / dl y el recuento de leucocitos era normal. La VSG era de $50 \mathrm{~mm}$ la primera hora. El INR era de 2,5, ajustado a la toma de acenocumarol. La bioquímica, los iones y transaminasas eran normales. El sedimento urinario no mostraba alteraciones. Factor reumatoide, crioglobulinas, anticuerpos antinucleares (ANA), anticuerpos anticitoplasma del neutrófilo (ANCA), antimembrana basal glomerular, antiperoxidasa, antihistona, anti-Ro, anti-SSA y antiSM fueron normales o negativos. Gasometría arterial $\mathrm{FiO}_{2}$ 0,21: $\mathrm{pH} 7,53$, $\mathrm{pO}_{2} 65 \mathrm{mmHg}, \mathrm{pCO}_{2} 39 \mathrm{mmHg}$. El electrocardiograma fue normal y en el ecocardiograma se confirmaba una válvula aórtica bicúspide sin otras alteraciones. La radiografía de tórax presentaba infiltrados alveolares bilaterales con silueta cardiaca normal. Los hemocultivos y el cultivo de esputo para bacterias y mycobacterias fueron negativos.

La gammagrafía de ventilación/perfusión y el estudio con angiotomografia computada no mostraron datos de tromboembolismo pulmonar por lo que se suspendió el tratamiento anticoagulante y se inicio tratamiento con amoxicilina/ácido clavulánico con mejoría clínica y desaparición de la fiebre, pero persistiendo los esputos hemoptoicos y los infiltrados en la radiografía de tórax. Se realizó una broncoscopia en la que no se encontraron anomalías endoscópicas. El cultivo del broncoaspirado no mostró crecimiento para bacterias, hongos ni mycobacterias y en la citología no se observaron células malignas. La espirometría, volúmenes pulmonares y difusión fueron normales.

Tras el alta hospitalaria, el paciente continúa presentando esputos hemoptoicos. Una nueva tomografía axial computada con cortes de alta resolución (TACAR) refleja la presencia de infiltrados pulmonares bilaterales y vidrio deslustrado (Fig. 1). Una nueva broncoscopia no mostró alteraciones intrabronquiales y el lavado broncoalveolar (LBA) mostró 512 células/ml: polimorfonucleares neutrófilos $1 \%$, polimorfonucleares eosinófilos $1 \%$ e histiocitos $98 \%$. La tinción con azul de Prusia mostró un $80 \%$ de hemosiderófagos.

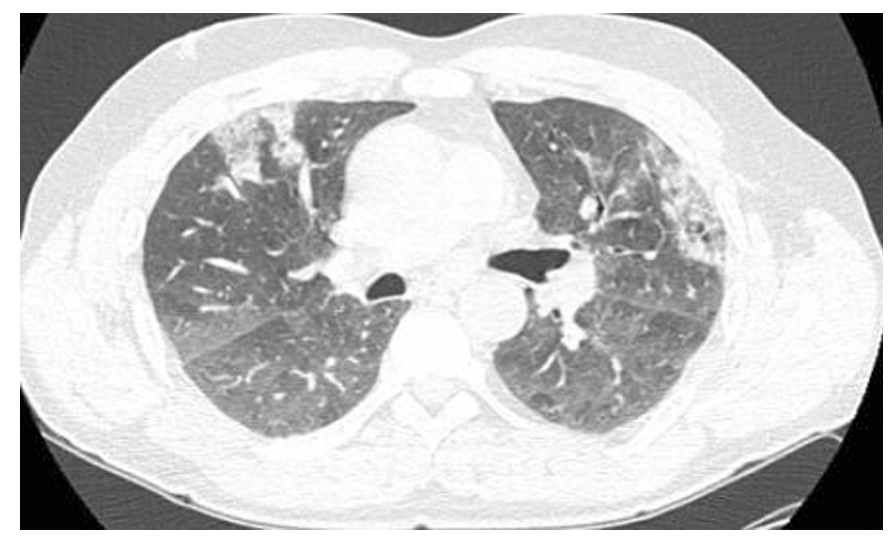

Fig. 1. TAC de alta resolución tórax. Infiltrados alveolares bilaterales con áreas de vidrio des/ustrado.

En sangre periférica persistían elevados los niveles de anticuerpos anticardiolipina y anticoagulante lúpico. Con los hallazgos descritos el paciente fue diagnosticado de síndrome antifosfolípido primario y hemorragia pulmonar secundaria, reiniciándose tratamiento con acenocumarol y ácido acetilsalicílico. Durante un año de seguimiento ha presentado esputos hemoptoicos ocasionales, pero la radiografía de tórax y la función pulmonar (espirometría, difusión y gases arteriales) se mantuvo normal y únicamente en el TACAR se observan algunas áreas de vidrio deslustrado.

\section{DISCUSIÓN}

Las principales formas de afectación pulmonar del SAF son el tromboembolismo pulmonar y la hipertensión pulmonar tromboembólica (3). La hemorragia alveolar (HA) es una manifestación infrecuente, que se ha descrito fundamentalmente en pacientes con síndrome antifosfolípido secundario a lupus eritematoso sistémico (LES), aunque recientemente también se ha observado esta complicación pulmonar en pacientes con síndrome antifosfolípido primario (9).

La hemorragia alveolar puede observarse en diferentes enfermedades: infecciones, enfermedades inflamatorias y en otras entidades no inflamatorias. El diagnóstico requiere descartar hemorragia procedente del árbol bronquial y demostrar más del $20 \%$ de hemosiderófagos en el lavado broncoalveolar (LBA) (10). En nuestro paciente no observamos alteraciones en la mucosa bronquial, el porcentaje de de hemosiderófagos en el LBA fue del $80 \%$ y las tinciones y cultivos no demostraron infección. También excluimos el tromboembolismo pulmonar ya que la gammagrafia y angiotomografía fueron normales. La insuficiencia cardiaca y la alteración en la coagulación también pueden causar hemorragia alveolar. Las alteraciones valvulares se observan en el 35\% de los pacientes con SAF primario (11), fundamentalmente en los casos con trombosis arterial. Este paciente presentaba una alteración valvular congénita pero sin repercusión hemodinámica, como se evidenció en la ecocardiografía, por lo que es muy improbable que esto sea la causa de la hemorragia alveolar.

En la mayoría de los casos la HA se presenta en pacientes previamente diagnosticados de SAF primario, si bien hay tres casos en los que esta complicación fue la primera manifestación de la enfermedad $(9,12)$. El espectro clínico de la HA en 
TABLA I

RESUMEN DE LOS CASOS DESCRITOS EN LA LITERATURA

\begin{tabular}{|c|c|c|c|c|c|c|c|c|c|}
\hline Autor y año & $N$ & Edad/sexo & $\begin{array}{l}\text { Clínica previa por el } \\
\text { SAF }\end{array}$ & $\begin{array}{l}\text { Ac. lúpico } \\
\lg G / \lg M\end{array}$ & $A C C$ & BAL & Biopsia & Tratamiento & Evolución \\
\hline Hillerdal (1991) & $\begin{array}{l}1 \\
2\end{array}$ & $\begin{array}{l}43 / \mathrm{H} \\
42 / \mathrm{H}\end{array}$ & $\begin{array}{l}\text { ACV, IAM } \\
\text { Claudicación intermitente } \\
\text { Trombosis arterial renal }\end{array}$ & $\begin{array}{l}+ \\
+\end{array}$ & $\begin{array}{c}\lg G \\
\lg C / \lg M\end{array}$ & $\begin{array}{l}\mathrm{NE} \\
\mathrm{NE}\end{array}$ & $\begin{array}{l}\text { Hemorragia alveolar } \\
\text { NE }\end{array}$ & $\begin{array}{l}\text { GC. CFM } \\
\text { GC. CFM }\end{array}$ & $\begin{array}{c}\text { No recidiva } \\
\text { Recidiva }\end{array}$ \\
\hline Getmer (1993) & $\begin{array}{l}1 \\
2 \\
3\end{array}$ & $\begin{array}{l}47 / H \\
21 / M \\
41 / H\end{array}$ & $\begin{array}{l}\text { Convulsiones, TVP } \\
\text { ACV, Abortos } \\
\text { Convulsiones, ACV } \\
\text { Livedo reticularis }\end{array}$ & $\begin{array}{l}+ \\
+ \\
+\end{array}$ & $\begin{array}{l}\lg C \\
\lg C \\
\lg C\end{array}$ & $\begin{array}{l}\mathrm{NE} \\
\mathrm{NE} \\
\mathrm{NE}\end{array}$ & $\begin{array}{l}\text { Capilaritis } \\
\text { Microtrombosis } \\
\text { Capilaritis } \\
\text { Microtrombosis }\end{array}$ & $\begin{array}{l}\mathrm{GC} \\
\mathrm{NE} \\
\mathrm{GC}\end{array}$ & $\begin{array}{l}\mathrm{NE} \\
\mathrm{NE} \\
\mathrm{NE}\end{array}$ \\
\hline Crausman (1995) & 1 & $56 / M$ & $\begin{array}{l}\text { TVP, Trombosis Aorta, } \\
\text { ACV }\end{array}$ & NE & $\lg C$ & $\mathrm{Si}$ & $\begin{array}{l}\text { Capilaritis. Hemorragia } \\
\text { alveolar. Vasculitis }\end{array}$ & CC. CFM & Recidiva \\
\hline Waterer (1999) & 1 & $57 / M$ & $\begin{array}{l}\text { TVP } \\
\text { TEP }\end{array}$ & $\mathrm{NE}$ & $\lg C$ & Sí & $\begin{array}{l}\text { Capilaritis } \\
\text { Hemorragia alveolar }\end{array}$ & CC & Recidiva \\
\hline Certner (1999) & $\begin{array}{l}1 \\
2 \\
3 \\
4 \\
5\end{array}$ & $\begin{array}{l}50 / M \\
48 / M \\
40 / M \\
47 / H \\
47 / H\end{array}$ & $\begin{array}{l}\text { TEP, ACV } \\
\text { TVP, ACV } \\
\text { ACV, } \\
\text { TVP, IAM } \\
\text { ACV }\end{array}$ & $\begin{array}{l}+ \\
+ \\
+ \\
+ \\
+\end{array}$ & $\begin{array}{l}\text { NE } \\
\text { NE } \\
\text { NE } \\
\text { NE } \\
\text { NE }\end{array}$ & $\begin{array}{c}\mathrm{NE} \\
\mathrm{SI} \\
\mathrm{NE} \\
\mathrm{SI} \\
\mathrm{NE}\end{array}$ & $\begin{array}{l}\text { NE } \\
\text { NE } \\
\text { NE } \\
\text { NE } \\
\text { NE }\end{array}$ & $\begin{array}{l}\text { GC } \\
\text { GC } \\
\text { CC } \\
\text { CC } \\
\text { CC. CFM }\end{array}$ & $\begin{array}{c}\mathrm{NE} \\
\text { No recidiva } \\
\text { Recidiva } \\
\text { Recidiva } \\
\text { Recidiva }\end{array}$ \\
\hline Al-Hajjaj (2000) & 1 & $27 / M$ & TVP & + & $\lg C$ & $\mathrm{NE}$ & $\begin{array}{l}\text { Hemosiderosis } \\
\text { Microtrombosis }\end{array}$ & CC. CFM & No recidiva \\
\hline Asherson (2001) & 1 & $63 / H$ & TVP, Trombosis arterial & $\mathrm{NE}$ & $\lg C$ & $\mathrm{NE}$ & Capilaritis & CC. Azatioprina & NE \\
\hline Martínez-Vázquez (2004) & $\begin{array}{l}1 \\
2\end{array}$ & $\begin{array}{l}33 / \mathrm{H} \\
89 / \mathrm{H}\end{array}$ & $\begin{array}{l}\text { Ninguna } \\
\text { Arteriopatia periferica }\end{array}$ & $\begin{array}{l}+ \\
+\end{array}$ & $\begin{array}{c}\lg C / \lg M \\
\lg C\end{array}$ & $\begin{array}{l}\mathrm{NE} \\
\mathrm{NE}\end{array}$ & $\begin{array}{l}\text { Hemosiderosis } \\
\text { No realizada }\end{array}$ & $\begin{array}{l}\text { GC. Azatioprina } \\
\text { No tratamiento }\end{array}$ & $\begin{array}{c}\text { No recidiva } \\
\text { Recidiva }\end{array}$ \\
\hline Deane (2005) & $\begin{array}{l}2 \\
3 \\
4\end{array}$ & $\begin{array}{l}39 \mathrm{H} \\
48 \mathrm{H} \\
44 \mathrm{H} \\
45 \mathrm{H}\end{array}$ & $\begin{array}{l}\text { Convulsiones } \\
\text { TVP } \\
\text { TVP } \\
\text { Ninguna } \\
\text { Ninguna }\end{array}$ & $\begin{array}{l}+ \\
+ \\
+ \\
+\end{array}$ & $\begin{array}{c}\lg C \\
\lg G / \lg M \\
\lg C \\
\lg M\end{array}$ & $\begin{array}{l}\text { si } \\
\text { si } \\
\text { si } \\
\text { si }\end{array}$ & $\begin{array}{l}\text { Capilaritis } \\
\text { Inmunoglobulinas } \\
\text { Capilaritis } \\
\text { Capilaritis } \\
\text { Capilaritis }\end{array}$ & $\begin{array}{l}\text { CC. CFM } \\
\text { CC. Micofenolato } \\
\text { CC. CFM } \\
\text { CC. CFM } \\
\text { Micofenolato } \\
\text { Hidrocloroquina }\end{array}$ & $\begin{array}{l}\text { Recidiva } \\
\text { Recidiva } \\
\text { Recidiva } \\
\text { No recidiva }\end{array}$ \\
\hline
\end{tabular}

$\mathrm{N}$ : número de casos; ACC: isoanticuerpos de anticardiolipina; SAF: síndrome antifosfolipido; TEP: tromboembolismo pulmonar; ACV: accidente cerebrovascular; NE: no conocido o especificado; CFM: ciclofosfamida; GC:glucocorticoides; BAL: lavado broncoalveolar; AC lúpico: anticuerpo lúpico; IAM: infarto agudo de miocardio.

el SAF primario puede extenderse desde una manifestación leve a un cuadro de insuficiencia respiratoria grave, como se observa fundamentalmente en el subgrupo de pacientes con el síndrome antifosfolípido catastrófico (4).

Desde el punto de vista histológico este síndrome puede agruparse en tres tipos de patrones: hemorragia sin alteración inflamatoria ni destrucción de septos alveolares, HA con un patrón histológico de síndrome de distrés respiratorio y HA con capilaritis $(9,13-16)$. En la HA secundaria a enfermedades autoinmunes la alteración histológica predominante es la vasculitis. En el SAF primario Gertner y Lie (17) describieron tres casos de hemorragia pulmonar cada uno con diferentes alteraciones histológicas: un caso con capilaritis, otro con microtrombosis vascular y en el tercero había microtrombosis y capilaritis. En la revisión de la literatura se aporta la histología en 14 casos y las alteraciones histológicas que predominaban eran la capilaritis con hemorragia en el espacio alveolar y en dos casos microtrombosis vascular (Tabla I).
Nuestro paciente reúne los dos criterios principales de síndrome antifosfolípido: trombosis venosa y presencia en suero de anticuerpos anticardiolipina y anticoagulante lúpico (1). En este paciente no hay datos clínicos ni serológicos de enfermedad autoinmune y por ello creemos que se trata de un paciente con un SAF primario.

En nuestro caso no disponemos de biopsia pero el diagnóstico de hemorragia alveolar quedó documentado por la demostración en el LBA de un alto porcentaje de hemosiderófagos. Una situación similar se ha descrito en 8 casos de la literatura $(6,9,14,15)$.

La pauta terapéutica más utilizada son los glucocorticoesteroides y la ciclofosfamida, con buena respuesta inicial al tratamiento pero con recidivas frecuentes $(6,7,9,13,15)$. También se ha empleado tratamiento con azatioprina, inmunoglobulinas, micofenolato y en un caso hidrocloroquina (9) (Tabla I).

En resumen, el espectro clínico de la hemorragia alveolar en el SAF primario es amplio. La broncoscopia y el LBA permiten confirmar el síndrome de hemorragia alveolar y ayudan 
a excluir otras causas de hemorragia pulmonar. La biopsia pulmonar es el "gold standard" para confirmar el diagnóstico de HA, pero el patrón histológico no es específico de este síndrome y probablemente añade un riesgo evidente. En ese sen- tido creemos que si las manifestaciones clínicas y otras pruebas complementarias son compatibles con HA secundaria a SAF este diagnóstico puede asumirse sin realizar biopsia pulmonar.

\section{Bibliografía}

1. Greaves M, Cohen H, Machine SJ, Mackie I. Guidelines on the investigation and management of the antiphospholipid syndrome. Br J Haematol 2000; 109: 704-15.

2. Grossman JM. Primary versus secondary antiphospholipid syndrome: is this lupus or not? Curr Rheumatol Rep 2004; 6: 445-50.

3. Espinosa G, Cervera R, Font J. El pulmón en el síndrome antifosfolípídico. Arch Bronconeumol 2002; 38: 27-32.

4. Asherson RA, Cervera R, Piette JC, Font J, Lie JT, Burcoglu A, et al.Catastrophic antiphospholipid syndrome. Clinical and laboratory features of 50 patients. Medicine (Baltimore) 1998; 77: 195207.

5. Al-Hajjaj MS. Massive pulmonary hemorrhage in a Saudi female with primary antiphospholipid syndrome. Saudi Med J 2000; 21: 777-9.

6. Gertner E. Diffuse alveolar hemorrhage in the antiphospholipid syndrome: spectrum of disease and treatment. J Rheumatol 1999; 26: 8057.

7. Hillerdal G, Hagg A, Licke G, Wegenius G, Scheibenpflug L. Intraalveolar haemorrhage in the anticardiolipin antibody syndrome. Scand J Rheumatol 1991; 20: 58-62.

8. Ghosh S, Walters HD, Joist JH, Osborn TG, Moore TL. Adult respiratory distress syndrome associated with antiphospholipid antibody syndrome. J Rheumatol 1993; 20: 1406-8.

9. Deane KD, West SG. Antiphospholipid antibodies as a cause of pulmonary capillaritis and diffuse alveolar hemorrhage: a case series and literature review. Semin Arthritis Rheum 2005; 35: 154-65.
10. De Lassence A, Fleury-Feith J, Escudier E, Beaune J, Bernaudin JF, Cordonnier C. Alveolar hemorrhage. Diagnostic criteria and results in 194 immunocompromised hosts. Am J Respir Crit Care Med 1995; 151: $157-63$.

11. Brenner B, Blumenfeld Z, Markiewicz W, Reisner SA. Cardiac involvement in patients with primary antiphospholipid syndrome. J Am Coll Cardiol 1991; 18: 931-6.

12. Martinez-Vazquez C, Perez S, Bordon J, Ordi-Ros J, Ribera A, Lopez A. Pulmonary hemorrhage and anti-phospholipid syndrome. Rev Clin Esp 2004; 204: 528-31.

13. Crausman RS, Achenbach GA, Pluss WT, O'Brien RF, Jennings CA Pulmonary capillaritis and alveolar hemorrhage associated with the antiphospholipid antibody syndrome. J Rheumatol 1995; 22: 554-6.

14. Maggiorini M, Knoblauch A, Schneider J, Russi EW. Diffuse microvascular pulmonary thrombosis associated with primary antiphospholipid antibody syndrome Eur Respir J 1997; 10: 727-30.

15. Waterer GW, Latham B, Waring JA, Gabbay E. Pulmonary capillaritis associated with the antiphospholipid antibody syndrome and rapid response to plasmapheresis. Respirology 1999; 4: 405-8.

16. Asherson, Ronald A.; Greenblatt, Michael A. Recurrent Alveolar Hemorrhage and Pulmonary Capillaritis in the "Primary" Antiphospholipid Syndrome. J Clin Rheumatol 2001; 1: 30-33.

17. Gertner E, Lie JT. Pulmonary capillaritis, alveolar hemorrhage, and recurrent microvascular thrombosis in primary antiphospholipid syndrome. J Rheumatol 1993; 20: 1224-8. 